\title{
$\left({ }^{\text {PSSR }}\right.$ \\ Pakistan Social Sciences Review www.pssr.org.pk
}

\section{RESEARCH PAPER}

\section{Vocational Education Practitioners Learning to Write Reflective Journal through Reflections on their Experiences during theCovid-19 Pandemic}

\author{
Gouhar Pirzada ${ }^{1}$ Yaar Muhammad*2 Faran Ahmed ${ }^{3}$
}

1. M. Phil Scholar, Department of Education, University of Management and Technology, Lahore, Punjab, Pakistan

2. Assistant professor, Department of Education, University of Management and Technology, Lahore, Punjab, Pakistan

3. M. Phil Scholar, Department of Education, University of Management and Technology, Lahore, Punjab, Pakistan

\begin{tabular}{|c|c|}
\hline $\mathrm{O}$ & CT \\
\hline & \multirow{17}{*}{$\begin{array}{l}\text { In the vocational education context, typical teaching and } \\
\text { learning patterns are getting obsolete, and new innovative } \\
\text { methods are being adopted to make the learning process more } \\
\text { effective. Among improved methods, reflective practices and } \\
\text { reflective journal writing are being adopted frequently for } \\
\text { continuous improvement. The practice of reflective journal } \\
\text { writing has the potential to change the dynamics of vocational } \\
\text { education. Six different types of reflective journal writing are } \\
\text { observed and discussed in this research study with the aim to } \\
\text { explore the participants' preferences for a certain type of journal } \\
\text { writing in addition to their reflections on teaching experiences } \\
\text { during the Covid-19 Pandemic. The participants view reflective } \\
\text { practices and reflective journal writing to be major } \\
\text { breakthroughs for improving teachers' self-efficacy as well as for } \\
\text { enhancing their roles for the better quality of vocational training } \\
\text { delivery. It is argued that the expected benefits of encouraging } \\
\text { the culture for writing reflective journals do not only benefit the } \\
\text { journal writers, but it can be very useful in providing an agenda } \\
\text { for the organization for its continuous improvement. }\end{array}$} \\
\hline & \\
\hline & \\
\hline & \\
\hline & \\
\hline 2021 & \\
\hline & \\
\hline & \\
\hline Reflective Journals, & \\
\hline & \\
\hline & \\
\hline & \\
\hline & \\
\hline & \\
\hline & \\
\hline & \\
\hline & \\
\hline
\end{tabular}

\section{Introduction}

The educational system in the world has transformed into more creative trends of learning instead of depending on conventional methods and sometimes obsolete knowledge(Varghese \& Mandal, 2020; Morley \& Jamil, 2021). The evolution of critical thinking has given more emphasis on research-based teaching (Naseer, Muhammad, \& Masood, 2020; Jamil, Muhammad, Masood, \& Habib, 2020). Educators need to frame their teaching that includes experiential-based learning to 
divert from the obsolete methods of learning and improve teaching methods(Roberts \& Westville, 2008; Akhtar, 2020).

The trend of incorporating unconventional methods of teaching is getting higher with all its merits of transforming the learning experience more attractive and beneficial(Akhtar, 2020). Some of the widely recognized methods include group and panel discussions, presentations, debates and speeches, film viewing, roleplaying, and recording the events to create references and later using these references to reflect on learning and practices. Reflective practices are becoming more common and appreciated for accelerating cognitive learning (Khan, Fazal, \& Amin, 2014). Reflective practice is learning through experience towards gaining new insights into self and practice(Ghaye, 2010; Candy, 2020).

Reflection is mirroring of the learning in one's actions. Reflective practice is a functioning and unique activity-based phenomenon that enables the moral arrangement of abilities set progressively to manage genuine, perplexed, and troublesome circumstances(Dixon, Lee, \& Corrigan, 2021). Frequently depicted as an individual instrument that teachers can use to notice and assess how they act in their classrooms, reflective practice can be both a private interaction just as one that they examine with associates or potentially pioneers (Roberts \& Westville, 2008; Zwozdiak-Myers, 2018). Teachers who are conscious of the impact of their practices consider this phenomenon useful and conversable with associates. Importantly, without satisfactory time and design spent on or talking about what has occurred, these discussions donot assist teachers with improving their training (Kaasila \& Lauriala, 2012).

Reflection is important to develop one's values, beliefs, attitudes, and behaviors(Godinez Martinez, 2017). It is an essential element of the learning process that is done directly or indirectly. It helps in developing new perceptions to decide future outcomes and improves our understanding of future practices. The reflection shows that the topics worked all through the content are significant and serve to stamp future works trying to develop their pragmatic pertinence in current settings (Ghaye, 2010). It is imperative to develop the conversation of the topics in the public setting, and particularly in various other education sectors, including technical \& vocational education and training. Practices learned from these institutes can be modeled for conventional schooling with set curriculums as well, and it might likewise be reached out to different nations where distinctive developmental societies are noticed (Kaasila \& Lauriala, 2012).

The learning processes being adopted in teaching, particularly in the vocational education sector, involve an even stronger reflection due to the nature of practicality and functioning of potentially all three learning domains; cognitive skills, psychomotor skills, and affective skills. The reflections from these experiences shape observations, which are responsible for furthering learning and development opportunities. These observations could develop either before the particular event or after that event (Roberts \& Westville, 2008). In the vocational education context, 
self-development and differences between routine actions are the key factors that create a need to involve reflection. Reflection is a mindset and attitude that encourages considering all the outcomes for actions, their consequences, and their analysis that help in developing a deeper understanding and future amendments of the particular practice. Ultimately, reflective practices suggest future actions after analyzing learner's experiences (Ghaye, 2010).

In the backdrop of vocational education, reflective practice is the teacher's ability to observe the particular problems and then find an innovative solution that could encourage students to deliver positive outcomes in a healthy environment. However, there is a need for deeper analysis, closer observation, and more experience (Kaasila \& Lauriala, 2012). Reflective teachers are always ready to learn from their personal experiences and then work for the betterment of the community. Their behaviors could act as an important aspect for students and for the community that further leads towards the development of society. These behaviors would encourage the development of common practices as reflection is not only limited to one profession (Killeavy \& Moloney, 2010).

Vocational education practitioners may face multiple issues in implanting the learned practices in the real world of teaching. Notably, the training institutes' environments could be a potential hindrance for adopting the methodologies, variant from the conventional methods (Khan et al., 2014). Particularly in the vocational education sector, it has been a major challenge to the teachers. Teachers try to opt for a track that would encourage students towards learning. Sometimes, teachers face challenges in the teaching process that include emotional regulation, creativity, conflict resolution, and emotional regulations that become hard for them to grasp (Kaasila \& Lauriala, 2012). Teachers in vocational education institutes need skills to have effective mind and emotion regulation exercises to have enough capacity to deal with different stakeholders that include students, colleagues, parents, administration, industry, and society. Students are the first stakeholder, and they must be treated equally according to their backgrounds, willingness to learn, and emotional level. These tasks can be challenging and equally exhausting, and therefore the teaching practices must involve reflection. Initially, reflective practices are difficult to handle, but after some time,they could be easily reflected in the vocational educational sector (Zeichner \& Liston, 2013).

Reflective practice in teaching isnot only significant for educators and institutes. It is a long-term process with a remarkable future that motivates the practitioner to analyze new knowledge and gain a deeper understanding of the teaching process. It needs cognition and emotions to be used interactively. Putting resources into the ability's improvement of a country through vocational training is a basic segment of human resources advancement. Networks hold specialized and vocational training in scorn, and this has brought about a deluge of people who are taking a crack at colleges, at last, bringing about high joblessness. The high joblessness is exacerbated by the abilities hole that exists in the country where 
various alumni are directed out yet without abilities that address the issues of the economy. The need to fabricate certainty is established in the examples of overcoming adversity of nations that put emphasis on specialized and vocational training as the course of giving basic abilities to industry. A purposeful interest in vocational training organizations by the authorities and the private sector is essential in propelling the improvement plan on human resources advancement in developing countries (Kaasila \& Lauriala, 2012). The focus of vocational institutes as an area of competency is to provide a skilled workforce to the labor market. Availability of competent human resources has always been a key challenge for vocational education providers.

Vocational education in a country like Pakistan is considered a cornerstone for its functional economy. Pakistan currently has the largest generation of young people in its history. This "youth lump" gives remarkable difficulties just as promising circumstances for the nation's social and financial advancement. Pakistan's vocational education and training system is confronting numerous difficulties, including access, quality, value, and importance to the industry. The vocational sector supplies several trained workers who are learned not only with conventional education but they have experienced hands-on learning and practical exposure as well. They gain knowledge of existing trends of industry by using modern tools, techniques, and equipment used in the work industry (Roeser, Skinner, Beers, \& Jennings, 2012). For better learning of skills, the methods used in our vocational training sector are designed by indulging newly trending practices like reflective learning also because it prepares the students to learn new skills that help them to build their careers. Their successful careers add up to the growth of the industry. What is required by vocational education practitioners is to make this technique of teaching productive since the focus ought to be adopting useful ways of teaching for producing a highly skilled and competent workforce. However, reflective practices are not encouraged in most vocational education, and the reason behind this is a lot of effort and time (Roeser et al., 2012).

There could be resistance among some teachers towards upgrading themselves and learning new knowledge since they are not willing to invest their time and efforts. The challenges of the teaching profession are categorized into three main domains. First, it demands patience that the teacher had to show. Second, it is emotional behavior that could be positive or negative according to the particular situation. Third, the teacher's expectations from the institute that they need to perform effectively. These challenges could increase the stress that reduces the teacher's intention to perform with innovation and creativity.

Reflective practice is the ability to reflect on one's actions to engage in the process of continuous learning. It occurs spontaneously as well as in essential planned reflection time. Argumentatively, the reflective educational program favors and is supported by a reflexive work on, considering the multifaceted nature of the circumstances, elements comprehended as animating the advancement of 
fundamental skills for the advancement of professional education in raising skilled technical. Reflective practice leads to action learning (Ghaye, 2010).

Besides other mechanisms, a reflective journal is a steadily growing document, now widely being used in the educational context(Moon, 2006; Rhodes \& Brook, 2021). Vocational practitioners can write to record the progress of their experiences and regularly learning in their journals. This type of journal is not simply a summary of the course material; it should also include the writer's reactions about what and how they developed their learning. Entries should be made regularly and perhaps at least once a week.

Various types of reflective journals(Ghaye, 2010). are stated below, along with their description. This serves as the main conceptual framework for this study to explore their application and utility in the context of vocational education.

Table 1

Six Types of Reflective Journals

\section{Reflective Journal Description}

types

Faithful

Regurgitation

The teaching profession demands commitment and honesty. This may count as the initial stage of the process of reflective practices. It can be accessed by the name of a method that requires a faithful description of events. This is a typical personal view recording process.

This type of recording of the journal also resembles the

Off-load regurgitation. Events are observed keenly, and feelings are monitored as and when they are felt. These entries are mostly personal and pertinent. The writer of the entries focuses on a particular part of the event.

This is a purely systematic and committed approach to

Extend and revise reflection-on-practice as it contains the past entries. It exists where the writer has made a large number of previous entries with time and date records or specified the entries with timelines. These entries are then recalled, revisited, reviewed, and re-appreciated to re-implement them to get better action plans.

Concept-mapping includes a picture and graphical objects to

Concept-mapping design the events. It is a more pictorial and graphical projection of thoughts than literary. The thoughts of the writer are framed by labeling the events stepwise.

Knots are described as interconnecting ties between cognitive

Knotty and messy and effective study. Knots can affect the quality of teaching verily as the interrelationship of both turns the outcomes different for various stakeholders.

Living contradiction refers to the contradiction which can be




\begin{tabular}{ll}
\hline Living & sighted by the stakeholders as there is an obvious difference \\
Contradiction & in saying and acting. This is the test of our values and beliefs. \\
& Writers have to go through the test for how far they can stand \\
& to or perform their uttered values themselves.
\end{tabular}

\section{Material and Methods}

A qualitative multiple case study research design(Stake, 2013; Yin, 2018) was adopted to understand the need for reflective practices in a vocational educational context. This research design helps in developing a rich understanding ofmultiple bounded cases(Miles, Huberman, \& Saldaña, 2020; Thomas, 2021). It helps to make assumptions from the personal experiences of the participants and the meaning given to those experiences (Merriam \& Tisdell, 2016; Yin, 2018).

The first researcher (GP) arranged a workshop for vocational education practitioners to familiarize the 30 participants with the concept of Reflective Practice and Reflective Journals. A presentation was designed to briefly guide participants about the various characteristics and features of reflective practices, the use of positive and reflective conversations, application of strengths-based reflection, reflective writing, and types of reflective journals that could be used for reflective writing. The variety of different experiences from the teachers' perspectives helps in analyzing the need for adopting reflective practices in our existing education sector. The full-day workshop was kept interactive with related videos and brainstorming activities to give maximum opportunities for participation. A template was designed by the researcher to explore participants' knowledge and understanding of the phenomenon. It also required participants to reflectively write about the past year's experiences of pandemic and online learning systems by choosing any of the taught types of a reflective journal. Data gained from these templates was rich, and it greatly helped to grasp the key ideas and perceptions of participants.

The social constructivist approach has been a guiding force while planning the methodologies and data collection processes. Since the research was planned to be conducted in the vocational education context, STEP Institute of Art Design \& Management was selected as the research site. The site selection proved an enabling factor since full access was given to the first researcher, and the institute, being the first vocational institute of the country to offer CBT (Competency-based training) in vocational education, was welcoming for capacity building of their staff. The institute is a pioneer among private sector TVET providers, offering various training programs since 2003. The 30 participants included full-time practitioners from various trades and departments of the institute (including the teaching staff, administrative staff, admissions and student services teams, IT support, and quality assurance departments). A purposive sampling technique was used for this research. The researcher collected data from 30 participants through a group session on the research site. 
Qualitative content analysis(Kyngäs, 2020) was used for analyzing data from The 30 participants. The filled templates collected from the research participants helped in understanding the reflective journal writing in the vocational education context.In addition, The 'within-case analysis' approach helped the researchers to explore the participants' preferences for a certain type of journal writing in addition to theirreflections on teaching experiences during the Covid-19 Pandemic.

\section{Findings}

The section reports qualitative content analysis was done using the data from the six participants who were selected to ensure all six types of reflective journals. Pseudonyms were given to each participant in order to hide their real identity and ensure their confidentiality and anonymity.

\section{Case study 1: BISMA}

Demographic profile: 30 years old, working full time as a teacher for Fine Arts and Visual Communication subjects, holds M. Phil. Degree in Fine Arts and is working with the institute for over two years. Type of reflective journal used: Offload type.

Bisma experienced a tough year due to pandemic and the introduction of online classes without much preparation, both at the individual and institutional level. She seemed to be quite upset about her own performance more than the performance of her students. Her subject of teaching required a much closer interaction with students. Reporting the difficulties, she stated,

Teaching drawing, at times, requires the teacher to hold the pencil or hand of students. The online system sounds great, but you cannot understand the music faced by teachers of practical and skill-based subjects.

Bisma chose the "Off-load" type reflective journal to state her experiences. She believed the last year to be full of surprises and uncertainty for her on personal and professional fronts. Her writing style and content depicted the traumatic situations she faced while teaching during the pandemic. The troubles that she faced while teaching practical subjects that are outcome-based are stated by her. She also complained about the lack of preparation at the institutional level as well as the lack of willingness by students who firmly believed they could not learn vocational skills through online learning. She also discussed the several efforts she made to try new ways of teaching online, including the set she specially designed at her home with the canvas at the background so she could paint on the spot and students could watch her drawing and painting skills, but that too, according to her, did not bring the desired motivation among her students. She felt good about learning the software and adding to her digital skills during the latter half of last year. 


\section{Case study 2: AKASH}

Demographic profiles: Lahore-based 27 years old male, working as an Admissions Coordinator in the institute for 1.5 years. He holds a Master's degree in Human Resources Management, and this is his first job. Type of reflective journal used: Knotty \& Messy type.

Akash considered the last year as a rollercoaster. He only joined the challenging role in the Admissions department a few months before the pandemic took over the control, and everything, according to him, transformed into situations that are usually watched as scenes of an adventurous film. He seemed to consistently deal with conflicts and confrontations throughout the year. He was just settling in his job role and was excited about resuming his first career job, and then everything changed for him due to the home-based online working. Quoting him, it was like somebody got trained to ride a cycle, and only when he learns cycling, all of a sudden, he is asked to drive a truck.

Akash reflected on his experiences of the past year using the knotty \& messy type of reflective journal. He expressed his views and unpleasant experiences of the changes that the pandemic brought in his working format. Convincing people online to take admission in a vocational career without meeting them in person doubles the trouble and made the task even more challenging. He was unhappy with the practices and lack of training provided to him during the initial phase of lockdown. Although the team was able to meet the annual targets, yet Akash was frustrated with the continuous lack of coordination and required support from technical departments. The MIS team, according to him, failed to get him access to the admissions \&inquiries database while working from home, and this wasted a lot of time and loss of potential admissions.

\section{Case study 3: NUMRA}

Demographic profiles: 42 years old UK-born woman with her education and initial working experience in the UK, working as Team Leader of Student Services at the institute for over four years. Type of reflective journal used by participant: Faithful regurgitation.

Numra seemed to love writing and recalling her experiences that she encountered during the last year. Her experiences were dominated by two major issues:Her restless struggle to reach out to students who desperately needed support during the lockdown while pursuing online education, and second her trust deficit issues with some staff members. The positive aspect remained her confidence that she believed to earn after working hard and coping up with all the pressure to work from home. Her family life was affected as her job required her to continue communicating and talking to students. 
Looking at Numra's journal, it was felt she had a lot to state about, but the two issues stated above. At one stage, it seemed as if journal-writing acted as her catharsis. In her perceptions, she made sincere efforts to be friends with everyone at her workplace, but this did not favorably happen. At one place, she wrote:I am constantly reminded that I need tolet go to build a cordial relationship with everyone at work, but building trust has always been a major issue for me throughout my life.

\section{Case study 4: JAMSHED}

Demographic profiles: 36 years old man, Lahore based, graduate with professional qualifications in Interior Design, working as Academic Coordinator in the institute for 9 years.Type of reflective journal used by participant: Extend and revised.

Jamshed reflected on the last year as the year of exploration and development. He stated contentment with the professional development that he acquired. The pandemic did not stop him from growing further in his role to ensure quality standards for various outcome-based vocational qualifications being offered by the faculty as per the standards set by international awarding bodies. Not only did he learn various softwares for effective online teaching, but he enabled teachers and assessors by training and supporting them. He took several initiatives specifically to emphasize online vocational learning, including the use of a tripod camera in the personalized home-based setup.

Jamshed chose to write the 'Extend and revised' type of reflective journal, which showed his consistency in recording important events, happenings, achievements, and major challenges that he faced in the past. His writing expressions were not only convincing but futuristic too. He tended to develop logical connections of past events with future expectations. He also mentioned some incidences about his colleagues and the ways through which he helped them to cope up with the pressures and challenges of online teaching. His journal showed the continuity of efforts and initiatives that he took, and occasionally, he edited the previous entries too, which showed his thoughtfulness and keen consideration towards recording his memories. Jamshed's reflections projected a mix of different feelings, dominated mainly by his celebrative expressions. He acknowledged the collaborative learning that helped the whole team to survive the unexpected and sudden shift to online teaching. In his own words,

Despite all the uncertainty, confusion, and chaos, I will remember the year 2020 for making me realize my hidden potentials. We became the first center to arrange the online Art $\mathcal{E}$ Design virtual exhibition. It all happened because of the excellent teamwork, and I feel happy to share my bits. 


\section{Case study 5: SEEMI}

Demographic profiles: 32 years old female, holding MFA Graphic Design degree, working as Teacher and Graphic Design Coordinator with the institute for around 8 years. Type of reflective journal used by participant: Living contradiction.

Seemi's reflections of the previous year were mostly occupied by the tough times she faced unhappy students who constantly complained about not being able to learn online. She also expressed her concerns about not getting sufficient time to plan for every class. To Seemi, most parts of the year were a waste of time. However, she did mention the extra efforts she had to ensure she was able to cover all the learning outcomes. On the whole, she didn't seem too happy with her performance as a teacher for Product Design, Packaging, and Print Media Design subjects. She recalled the long calls and exchange of messages she had with students individually to re-explain things that were not clear to them during online classes. She had an unrest year at the personal level as well because of her parents' ailment, and she partially blamed herself for not being able to keep the balance between her personal and professional life.

Seemi's reflections explicitly categorized the 'Living contradiction' reflective journal type. She kept on stressing the amount of anxiety she had to go through as initially, she did not seem to have any clue about how to teach the software-oriented practical subjects online. Her usual practice would be doing the task herself and then asking students to demonstrate individually. Apparently, this methodology did not work for her. Yet, she later confessed to being too lazy with the orientation to online teaching. She stated: I feel guilty for being too passive in adopting technological transformations. In the beginning, I just thought it's going to last for a couple of weeks.

Looking back, she accepted the contradictions in her concerns and actions towards the whole experience. Although she justified her weaker performance and poor students' feedback to circumstances that were beyond her control; nevertheless, she also realized her shortcomings.

\section{Case study 6: FAMIA}

Demographic profiles: 29 years old female, holding MFA in Textile Design, working as full-time teacher for various subjects being taught under the Textile Design stream of courses, working with the institute for over three years.Type of reflective journal used: Concept-Mapping.

Famia's choice of the Concept-Mapping reflective journal was compatible with her very strong visual skills and presentation of thoughts and ideas that she linked with all aspects of her personality while evaluating herself during the past year. She figured she needed to work on her 'anger management.' The year didnot prove to be her best year. Her routine got upset, and this affected her behavior with frequent mood swings and short temperateness. 
The pandemic and all its associated issues like the lockdown, no social activities, discontinuation of her gym sessions, and online teaching seemed to accelerate tensions and anger for her. She connected various issues she faced during the year, developed the nodes and relationship among all these issues that clearly portray how the presence of all these factors further deteriorated the situation for her. This is evident from the below extract of her figurative reflections:

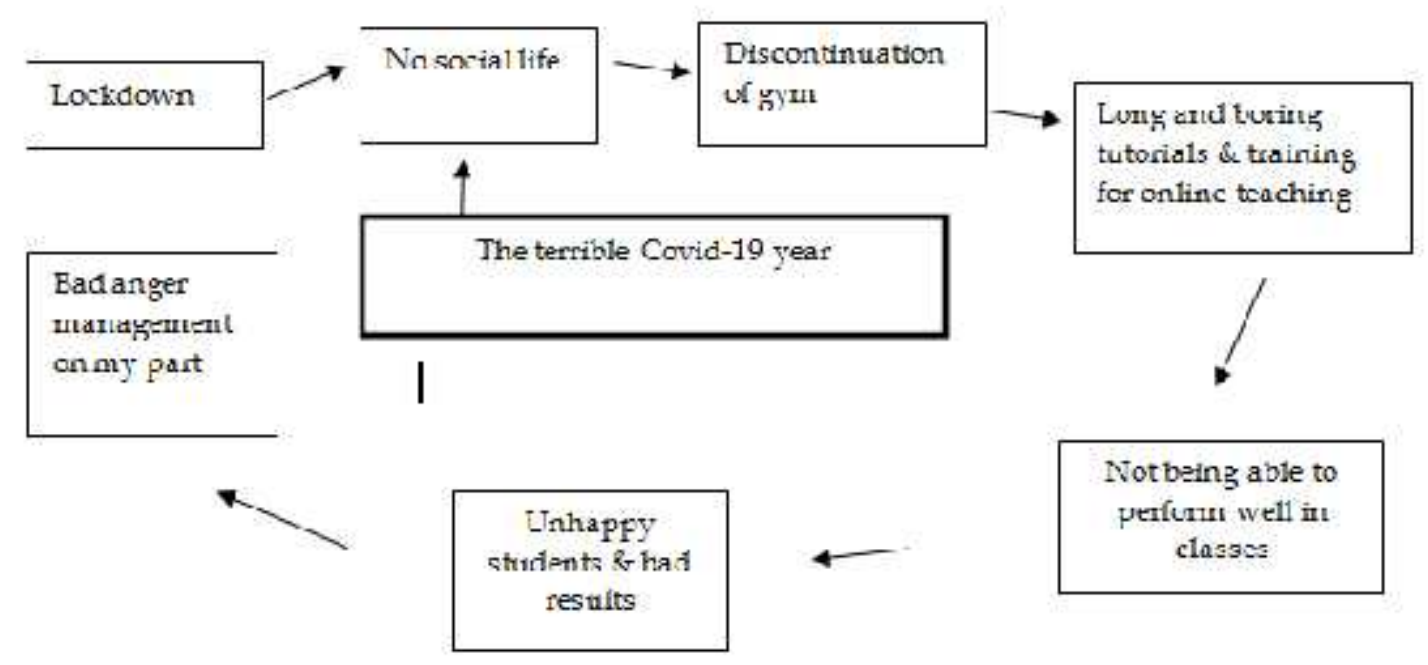

\section{Discussion}

Various types of reflective journals were used by the participants, and each of these journals enabled them to think critically and reflect on their experiences. Issues that are highlighted in all of these journals are not only significant for developing potential competencies for these individuals, but they certainly provide a good base for improving the overall institute's quality of vocational education, specifically for the online training scenario. Entries from each of these reflective journal types are discussed below.

\section{Faithful Regurgitation Type of Reflective Journal}

Numra chose to share her experiences with faithful regurgitation in the third case. She followed descriptive reflections-on-practice, wrote vividly, and centrally observing her own self for the course of actions in the event. The overall emphasis of her entry was upon what she did. Events were written down sequentially with their true impact of being good or bad. The experiences discussed included the importance of group-based learning, personal training to increase efficiency, achieving deadlines, students' engagement in online education, relationship building, and personal satisfaction. Numra shared that despite being an openminded and forgiving human being, sometimes she failed when she had to deal with issues of building trust again at the workplace. She was willing to build an environment that would help students to learn more. Numra's reflections were 
certainly the typical personal views recording process. In the faithful regurgitation reflective journal, the writer acts as the first observer, but this also needs a keen observation of the event. The feeling at every moment of the occasion is monitored by the observer (Ghaye, 2010).

\section{Off-Load Type of Reflective Journal}

Bisma wrote her experiences using the Off-load type reflective journal, explained in the first case. The type of entries in this reflective journal type are highly related to the emotions of the writer, and it may have an impact on the mental state of the writer. It can make the writer happy, sad or can leave them in a confused or regretful mood, which is evident from Bisma's writings. Although she seemed to finally develop her liking for effectively teaching online, her initial negative emotions and discontentment about the performance of students remained actively dominating her journal. She categorically discussed the need for improvement in her teaching skills and online teaching practices. She discussed key challenges, including an imbalance between her personal and professional life, students' unwillingness to learn the vocational skills through online teaching, exceeding working hours, her initial lack of digital and technical skills, and lack of freedom while online teaching. Some of these views may not be accepted fully by the institute or its faculty. There are chances of judgmental entries, and they may not be agreed upon by the other stakeholders because they can contain disagreement of the teacher towards the event, educational practice, or policy (Ghaye, 2010).

\section{Extend and Revise Type of Reflective Journal}

The fourth case of Jamshed exhibited the use of Extend and revise reflective journal type. Considering the systematic and committed approach to reflection-onpractice that makes this type of reflective journal distinctive from others, the journal is written by Jamshed presented multiple emotions and sequential recording of various events that he experienced in the form of challenges of designing and maintaining the online vocational training. Usual of the opportunities provided by the 'extend and revise' journal entries, Jamshed kept recording events where he and the other faculty members upgraded their skills during the pandemic. With the passage of time, the design of training delivery and assessment methodologies were altered, and finally, the successful designs were implemented with a smooth flow of communication. It does not only give a chance to just alter the thought. It influences the emotions in a consequent way, such as the sense of correction and better understanding afterward give joy and makes the writer happy (Ghaye, 2010). Jamshed made multiple numbers of entries with time and date records against each of these. Some of these entries were also revisited and reviewed by the writer to reappreciate and re-implement the drafted action plans.

\section{Concept-Mapping Type of Reflective Journal}


Concept-mapping includes a picture and graphical objects to design the events. It is a more pictorial and graphical projection of thoughts than literary. The thoughts of a teacher are framed by labeling the event stepwise (Ghaye, 2010). It was used by Famia in the sixth case. Being an artist, she found it convenient to visually reflect her experiences and opinions, which made logical meaning of her thought process. Famia associated the pandemic with issues that she faced at personal and professional levels. In the center of her map, she wrote "the terrible year of Covid19 " and showed how this had a strong impact on her mental and physical health and how this led to dissatisfaction among students. Famia utilized the conceptmapping reflective journal in an effective manner. She pointed several issues that, according to her, were beyond a teacher's basic job, such as issues like downloading the recorded sessions and sharing with students and the monitoring team. She seemed upset because of the lockdown and discontinuation of her physical exercises that resulted in aggregating her issue of anger management. Her journal also reflected the connections between several teams and departments of the institute and their working patterns towards online learning management.

\section{Knotty and Messy Type of Reflective Journal}

This type was discussed in the second case, where the participant identified team work to be focused more than an individual's effort for the overall success of any organization. Afraz shared that he was only able to achieve the required targets by using his digital skills and gadgets that helped him recording his observations and sustaining contact with students. Various other challenges and internal organizational conflicts have also been pointed in his entry. Knots can affect the quality of teaching verily as it is the interrelationship of both. It turns the outcomes different for various stakeholders (Wagner, 1987). Knots are little hurdles that arise due to a discrepancy, conflict of asserted approach, or dilemma between 'what is' and 'what must or should be'. The phenomenon is evident from Akash's perspectives about the dire need of fully equipping staff to work online to meet targets. The issue of trust deficit among Pakistani students, in general, regarding online business activities was also highlighted.

\section{Living Contradiction Type of Reflective Journal}

Living contradiction refers to the contradiction which can be sighted by the stakeholders as there is an obvious difference in saying and acting. This is the test of our values and believes. Teachers have to go through the test for how far they can stand to or perform their uttered values themselves. Our fifth case of Seemi provided an example of this type. It is required that the teacher should carefully observe the actions according to their values when they have been practiced in any event (Ghaye, 2010). Seemi admitted in her journal that she was not motivated enough to take an extra mile to meet students' expectations in online teaching. However, she kept on blaming students initially. Seemi considered it a useful way, being a teacher, to realize and weigh her practices and chaos of personality, and during her counseling and feedback meetings with the HOD, she realized the gaps 
that she needed to fill. The positive aspect remained her efforts during the second half of the academic year, where she proved this realization not only in words but through her actions.

\section{Conclusion}

Reflective practices have provided a massive aid in the cognitive learning of both students and instructors. Vocational education practitioners can alter the typical methods of teaching and coordinate and make learning more efficient. Reflective journals enable practitioners to record their feelings, emotions, learning, challenges, accomplishments, and achievements, which are all outcomes of recalling sound observations by the writers. These records can effectively provide relevant support in similar future events. The regular practice of writing reflective journals certainly gives opportunities to teachers to recall, revisit and alter the decisions they have made in certain situations. The process greatly supports making the best choices for similar situations that happen again. In a way, reflective journal writing helps in a twofold manner; these can improve self-efficacy among practitioners about what has been achieved and how to plan for things that did not go right, and two, it can also serve as the basis of planning the continuous professional development. In this particular study, participants were able to throw the negative feelings and emotions out of their minds too. A lot of unwanted scenarios that most participants found themselves in were even beyond the control of the institute management. Nevertheless, entries provided by participants highlight significant issues and challenges that the institute management can look into for improving the overall performance of the online learning systems.

Additionally, the study has highlighted the challenges faced by practitioners, and quite a lot of these challenges can be addressed by the institute management. Internal collaboration, conflict management, sound staff orientation, and training for enhancing their digital learning, cooperation from the IT and technical teams, etc., are a few of these to name. In a nutshell, the expected benefits of encouraging the culture for writing reflective journals do not only benefit the journal writers, but it can be very useful in providing an agenda for the organization for its continuous improvement. However, it requires a culture of democracy and providing fair opportunities to share what they have observed, experienced, and reflected. 


\section{Recommendations}

Based on the study and views of the participants, the following recommendations are proposed for the effectiveness of reflective learning practices through reflective journal writing to help teachers and students at vocational training facilities:

It was found that practitioners were not initially familiar with the concept of reflective practicing and reflective journal writing. The practice should be encouraged to be applied for further utilization of this phenomenon.

Practitioners found the practice of writing reflective journals very useful in identifying the gaps and challenges that they have faced, and therefore, the practice of writing reflective journals should be strongly encouraged.

Teachers disclosed the lack of time and tight teaching schedules to be a major hurdle in continuing the practice of reflective journal writing. Decent time periods should be allocated to teachers to enable them to regularly writing journals.

The nature of vocational training demands frequent up-gradation of teaching practices and methodologies, which could result in frequent changes and resource up-gradation demanded by teachers and practitioners through their reflective journals.

Maximum benefits of reflective journal writing could be availed if practitioners are encouraged to share their thoughts and ideas with concerning supportive teams to avoid conflicts and sustain good practices.

The spirit and essence of reflective journal writing are to encourage practitioners to reflect on their actions through the lens of their values and beliefs. It is important to respect opinions and suggestions given by practitioners from the thought process they applied while writing reflective journals. Future studies could explore the application and utilization of reflective practice and reflective journal writing in public sector vocational institutes. Moreover, it will be very beneficial if institute principals are made aware of these practices, too so the practices are encouraged by them to be followed by teachers and other practitioners in their institutions. 


\section{References}

Akhtar, R. N. (2020). Exploring Experiential Learning Models and developing an EL based ERE cycle in teaching at higher education in Pakistan. International Journal of Experiential Learning $\mathcal{E}$ Case Studies, Dec., 250-264. doi:dx.doi.org/10.22555/ijelcs.v5i2.44

Candy, L. (2020). The creative reflective practitioner: Research through making and practice. London: Routledge.

Dixon, M., Lee, C., \& Corrigan, C. (2021). 'We were all looking at them quite critically': collaborative reflection on a university-based coach education program. Reflective Practice, 1-16.

Ghaye, T. (2010). Teaching and learning through reflective practice: A practical guide for positive action. New York: Routledge.

Godinez Martinez, J. (2017). An investigation into the cognitive transformation that English language teachers go through when engaging in collaborative reflective practice. (Unpublised doctoral dissertation), University of Southampton, Southampton.

Jamil, M., Muhammad, Y., Masood, S., \& Habib, Z. (2020). Critical thinking: A qualitative content analysis of education policy and secondary school science curriculum documents. Journal of Research and Reflections in Education, 14(2), 249258.

Kaasila, R., \& Lauriala, A. (2012). How do pre-service teachers' reflective processes differ in relation to different contexts? European Journal of Teacher Education, 35(1), 77-89.

Khan, M. I., Fazal, S., \& Amin, M. (2014). Reflection in teacher education programmes in Pakistan and the UK: A comparison. Journal of Research and Reflections in Education, 8(2), 132-138.

Killeavy, M., \& Moloney, A. (2010). Reflection in a social space: Can blogging support reflective practice for beginning teachers? Teaching and Teacher Education, 26(4), 1070-1076.

Kyngäs, H. (2020). Inductive content analysis. In H. Kyngäs, K. Mikkonen, \& M. Kääriäinen (Eds.), The application of content analysis in nursing science research (pp. 13-21). Switzerland AG: Springer Nature.

Merriam, S. B., \& Tisdell, E. J. (2016). Qualitative research: A guide to design and implementation (4th ed.). San Francisco, CA: John Wiley \& Sons.

Miles, M., Huberman, M., \& Saldaña, J. (2020). Qualitative data analysis: A methods sourcebook (4th ed.). New York: Sage Publications. 
Moon, J. A. (2006). Learning journals: A handbook for reflective practice and professional development. London: Routledge.

Morley, D. A., \& Jamil, M. G. (2021). Introduction: Real world learningrecalibrating the higher education response towards application to lifelong learning and diverse career paths. In D. A. Morley \& M. G. Jamil (Eds.), Applied Pedagogies for Higher Education Real World Learning and Innovation across the Curriculum (pp. 1-17). Cham, Switzerland: Palgrave Macmillan.

Naseer, H., Muhammad, Y., \& Masood, S. (2020). Critical thinking skills in a secondary school Pakistan studies textbook: A qualitative content analysis. sjesr, 3(4), 84-95.

Rhodes, J., \& Brook, C. (2021). Reflective journaling and WhatsApping as part of a management degree apprentice's action learning practice. Action Learning: Research and Practice, 1-9.

Roberts, C., \& Westville, I. (2008). Developing future leaders: The role of reflection in the classroom. Journal of Leadership Education, 7(1), 116-130.

Roeser, R. W., Skinner, E., Beers, J., \& Jennings, P. A. (2012). Mindfulness training and teachers' professional development: An emerging area of research and practice. Child Development Perspectives, 6(2), 167-173.

Stake, R. E. (2013). Multiple case study analysis. New York: Guilford Press.

Thomas, G. (2021). How to do your case study. London: Sage Publications Limited.

Varghese, N., \& Mandal, S. (2020). Teaching-learning and new technologies in higher education: An introduction. In Teaching Learning and New Technologies in Higher Education (pp. 1-15): Springer.

Yin, R. K. (2018). Case study research and applications: Design and methods (6th ed.). New York: Sage publications.

Zeichner, K. M., \& Liston, D. P. (2013). Reflective teaching: An introduction. New York: Routledge.

Zwozdiak-Myers, P. (2018). The teacher's reflective practice handbook: Becoming an extended professional through capturing evidence-informed practice. London: Routledge. 